\title{
High-temperature low-cycle fatigue behaviour of HIP treated and untreated superalloy MAR-M247
}

\author{
I. Šulák ${ }^{1 *}$, K. Obrtlík ${ }^{1}$, L. Čelko ${ }^{2}$ \\ ${ }^{1}$ Institute of Physics of Materials, Academy of Sciences of the Czech Republic, Žižkova 22, 61662 Brno, Czech Republic \\ ${ }^{2}$ Brno University of Technology, CEITEC, Technická 3058/10, 61669 Brno, Czech Republic
}

Received 30 May 2016, received in revised form 13 October 2016, accepted 19 October 2016

\begin{abstract}
The effect of hot isostatic pressing (HIP) treatment on high-temperature low cycle fatigue (LCF) behaviour of $\gamma^{\prime}$ precipitation strengthened nickel-based superalloy MAR-M247 was studied. Microstructural observations revealed coarse-grained dendritic structure with an average grain size of $2.1 \mathrm{~mm}$. Distribution and size of casting defects were assessed on cross sections of both HIP treated and untreated MAR-M247. Shape and size of precipitates were documented. Vickers hardness tests did not reveal differences between both materials. Untreated specimens were cyclically strained under total strain control at $900^{\circ} \mathrm{C}$. Likewise, tests were performed on the HIP treated material at temperatures of 900 and $950^{\circ} \mathrm{C}$. The stress-strain response was recorded. Coffin-Manson and Basquin fatigue life curves were established. HIP treatment leads to an increase of lifetime in comparison with the untreated material. Precipitate depleted zone was observed and crack initiation sites were identified. Dislocation arrangements were studied in TEM. Planar bands containing antiphase boundaries were observed.
\end{abstract}

K e y w o r d s: hot isostatic pressing, Ni-based superalloy, high-temperature low cycle fatigue, fatigue life curves, dislocation structures, planar bands

\section{Introduction}

Components of aircraft engines, turbochargers, power generation facilities, such as turbine blades and vanes, operate at high temperatures under complex cyclic and sustained loading. There is a strong requirement to increase the performance of power units. Advanced design and lighter constructions are one of the feasible possibilities to increase the efficiency of these devices. Another way is an increase of operating temperatures [1]. However, this requires the application of more durable and also costlier materials. In this regard, nickel-based superalloys have evolved into complex alloy systems with exceptional high-temperature strength, creep resistance, and fatigue behaviour [29]. Second-generation polycrystalline cast superalloy MAR-M247 becomes a perspective material that satisfactorily covers the needs of small power facilities and aircraft engines, and in the near future, it may fully replace material IN713 LC used so far. MAR-
-M247 was developed by Martin Marietta Corporation in the 1970s [10]. The microstructure of this precipitation strengthened nickel-based superalloy consists of the $\gamma$ matrix, and of intermetallic $\gamma^{\prime}\left(\mathrm{Ni}_{3} \mathrm{Al}\right)$ precipitates. Outstanding mechanical properties, oxidation resistance and structural stability at elevated temperatures are achieved through the appropriate combination of alloying elements [11]. The high content of tungsten ensures the stability and strength of the solid solution $\gamma$. The addition of tantalum and hafnium improves mechanical and thermal stability of $\gamma^{\prime}$ precipitates. Moreover, hafnium contributes significantly to the grain boundary strengthening $[4,12,13]$. A chemical composition as well as solidification variables and multiple heat treatments immensely influenced microstructure and mechanical properties [2, 14-17] and resulted in applications of the alloy at temperatures up to about $1038^{\circ} \mathrm{C}[18]$.

Gas turbine components made of MAR-M247 are usually produced by investment casting technique [14,

\footnotetext{
*Corresponding author: e-mail address: sulak@ipm.cz
} 


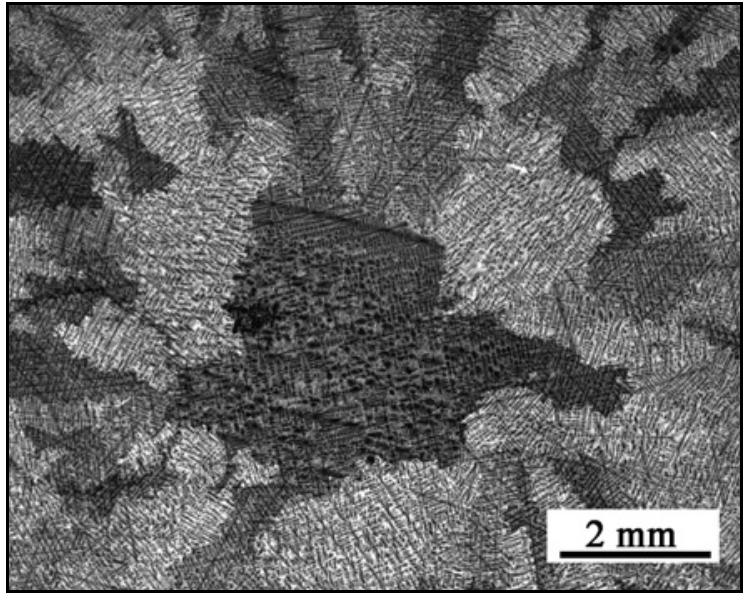

Fig. 1. The microstructure of MAR-M247 - dendritic structure of the HIP treated material in a section perpendicular to the specimen axis.

19] and subsequently heat treated $[15,16,20]$. Investment casting involves certain problems in terms of casting defects that cause perceptible scatter and reduction in fatigue life $[8,21,22]$ and can also significantly reduce the strength of the material. Incorporating hot isostatic pressing (HIP) technology in the production process leads to a reduction of porosity, shrinkages, and voids [23-25]. Despite the high precision and modern procedures, it is not possible to completely eradicate the casting defects [26].

In service, many critical turbine parts are subjected to repeated elastic-plastic straining as a result of heating and cooling during start-up and shutdown periods. Therefore, high-temperature low cycle fatigue (LCF) behaviour of material is considered to be an important area of interest. Thorough understanding of LCF damage behaviour is necessary to guarantee the safe design of components [27-30]. The present study reports the LCF behaviour of HIP treated and untreated MAR-M247 at 900 and $950^{\circ} \mathrm{C}$. Special attention is devoted to cyclic strain localization and fatigue crack nucleation using scanning electron microscopy (SEM) and transmission electron microscopy (TEM).

\section{Experimental procedure}

\subsection{Materials}

Polycrystalline nickel-based superalloy MAR-M247 was supplied in the form of casting rods by PBS, Velká Bíteš, a.s. The chemical composition of MARM247 superalloy used was obtained by chemical analysis and is as follows (in wt.\%): $0.15 \mathrm{C}, 8.37 \mathrm{Cr}$, $9.91 \mathrm{Co}, 9.92 \mathrm{~W}, 0.67 \mathrm{Mo}, 5.42 \mathrm{Al}, 1.01 \mathrm{Ti}, 3.05$ $\mathrm{Ta}, 0.04 \mathrm{Fe}, 0.015 \mathrm{~B}$ and $1.5 \mathrm{Hf}$ and $\mathrm{Ni}$ bal. The rods were produced by the technique of investment casting and their size and shape approach specimens for low cycle fatigue tests. All rods were delivered after two-stage heat treatment consisting of solid solution annealing $\left(1200^{\circ} \mathrm{C} / 2 \mathrm{~h}\right)$ and subsequent precipitation hardening $\left(870^{\circ} \mathrm{C} / 24 \mathrm{~h}\right)$. One-half of specimens underwent the hot isostatic pressing procedure $\left(1200^{\circ} \mathrm{C} / 100 \mathrm{MPa} / 240 \mathrm{~min}\right)$ prior to heat treatment. A detailed description of HIP and heat treatment can be found elsewhere [18]. The diameter and gauge length of test specimens with button ends used for clamping in special hydraulic grips was 6 and $15 \mathrm{~mm}$, respectively. The gauge length was mechanically ground to final roughness $R_{\mathrm{a}}=0.4$. Some specimens were electrolytically polished to facilitate surface relief observations. The average grain size obtained by linear intersect method is $2.1 \pm 0.3 \mathrm{~mm}$. The typical coarse-grained dendritic structure is shown in Fig. 1.

\subsection{LCF testing}

Three-zone resistance furnace controlled by three channels controller was used to heat test specimens to the required temperature. Temperature monitoring was performed using three thermocouples attached to both specimen ends and at the upper part of the gauge section. In addition, a control thermocouple was mounted at the lower end of the gauge section. During experiments, the temperature was kept constant at these locations in the interval of $\pm 1.5^{\circ} \mathrm{C}$. Test specimens were cyclically strained in an electro-hydraulic testing machine MTS 810 controlled with digital electronics Teststar IIs. The HIP treated material was tested at 900 and $950{ }^{\circ} \mathrm{C}$ whereas the untreated material only at $900^{\circ} \mathrm{C}$ for comparison. All tests were performed in a push-pull cycle under total strain control conditions. The longitudinal deformation was measured and controlled by an extensometer with a gauge length of $12 \mathrm{~mm}$ attached in the middle of specimens. The extensometer was equipped with ceramic extensions so that its sensitive electrical portion was located outside the furnace and held at a constant temperature by compressed air. Cyclic loading was carried out at a constant strain rate of $0.002 \mathrm{~s}^{-1}$ in a symmetrical fully reversed cycle $\left(R_{\varepsilon}=-1\right)$. Test control and data recording were provided by an MTS Company program. For a selected number of cycles, equal approximately to geometric progression (20 values per decade), digital forms of hysteresis loops (about 400 pairs of stress and strain) were recorded in an electronic memory. In addition, the control program evaluates the stress amplitude and the values of peak and valley stress and strain in each cycle particularly. The plastic strain amplitude equal to the half of the hysteresis loop width at the mean stress was evaluated later with a separate program using recorded hysteresis loops. The number of cycles to fracture $N_{\mathrm{f}}$ was de- 
termined as the number of cycles elapsed at the time of accomplishment of the criteria $\left(\sigma_{\mathrm{m}} / \sigma_{\mathrm{a}}\right)=-0.3\left(\sigma_{\mathrm{m}}\right.$ is the mean stress, and $\sigma_{\mathrm{a}}$ is the stress amplitude) or at the time when the fracture occurred before the completion of the test criteria. It corresponds to a fatigue crack extended approximately to half of the specimen circumference.

\subsection{Microstructural characterization}

Selected cross sections of fatigued and unfatigued specimens and fracture surfaces were observed using a fully PC controlled SEM with Schottky field emission cathode in combination with gallium Focused Ion Beam (FIB) column and with Gas Injection System (GIS) TESCAN LYRA 3 XMU with a maximum resolution of $1.2 \mathrm{~nm}$ at $30 \mathrm{kV}$. EDS detector Oxford XMAX which is built in the microscope was used for local chemical analysis. Gallium focused ion beam served to prepare thin lamellae to observe precisely defined locations on the surface. Thin lamellae and oriented foils were observed in transmission electron microscope Philips CM12 STEM with point-to-point resolution $0.3 \mathrm{~nm}$, using goniometer of large tilting range $\left( \pm 45^{\circ}\right.$ main tilt and $\pm 20^{\circ}$ transversal tilt) with a special focus on dislocation structure investigations and clarifying low cycle damage mechanisms of MAR-M247 at high temperatures.

\section{Results}

\subsection{Microstructure and defects}

The microstructure of the polycrystalline material MAR-M247 is shown in Fig. 1. It comprises coarse dendritic structure typical of cast alloys. Figure 2 shows details of the microstructure of the HIP treated material in a section perpendicular to the specimen axis. The arrangement and size of $\gamma^{\prime}$ precipitates in dendritic arms differ from those in interdendritic areas. Fine cuboidal precipitates with the average edge size of $0.5 \mu \mathrm{m}$ are found in dendritic arms while coarse (up to $5 \mu \mathrm{m}$ ) precipitates having a more complex shape are present in interdendritic areas as can be seen in Fig. 2a. Besides, spherical nanoprecipitates with a radius of $20-50 \mathrm{~nm}$ have been observed within the matrix (see Fig. 2b). Complex carbides (MC-type) containing hafnium and tantalum have been revealed in interdendritic areas at the interface of fine and coarse precipitates (see arrows in Fig. 2a) and at the grain boundaries. Also, $\mathrm{M}_{23} \mathrm{C}_{6}$ and $\mathrm{M}_{6} \mathrm{C}$ carbides containing mainly chromium and tungsten have been observed in agreement with literature data [31]. The volume fraction of precipitates and carbides morphology are independent of HIP treatment. During LCF tests, no directional coarsening of $\gamma^{\prime}$ precipitates was observed.
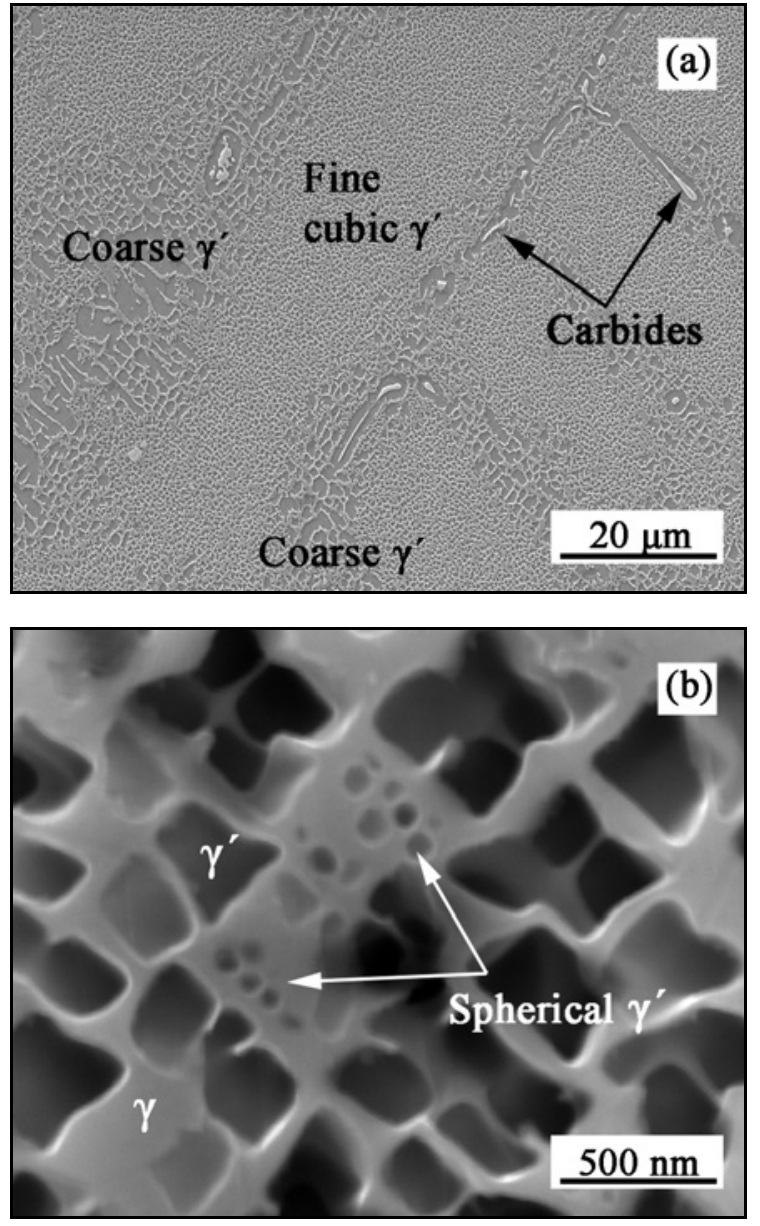

Fig. 2. MAR-M247 microstructure: (a) coarse and fine precipitates with the carbides, (b) detail of fine cubic and spherical precipitates.

A thin layer of the precipitates free (depleted) zone was observed close to the surface of fatigued specimens of both HIP treated and untreated material see Fig. 3. It is conspicuous that the depleted zone is developed as a result of the formation of a complex aluminium and chromium rich oxide surface film. This oxide film helps to protect the material against further degradation in aggressive high-temperature environments. However, once the crack is initiated, the protective oxide film is impaired and the crack surface depleted zone develops by the same mechanism. The oxide film, subsurface precipitate free zone and also depleted zone in a vicinity of the crack growing perpendicularly to the specimen axis are shown in Fig. 3a. Figure 3b shows relative concentrations of decisive elements (namely $\mathrm{O}, \mathrm{Al}, \mathrm{Cr}$, and $\mathrm{Ni}$ ) in the vicinity of the specimen surface and crack surface. The precipitates free zone varies in thickness with increasing temperature and is approximately up to 8 and $12 \mu \mathrm{m}$ at 900 and $950^{\circ} \mathrm{C}$, respectively. A similar reaction to high-temperature exposition was documented 

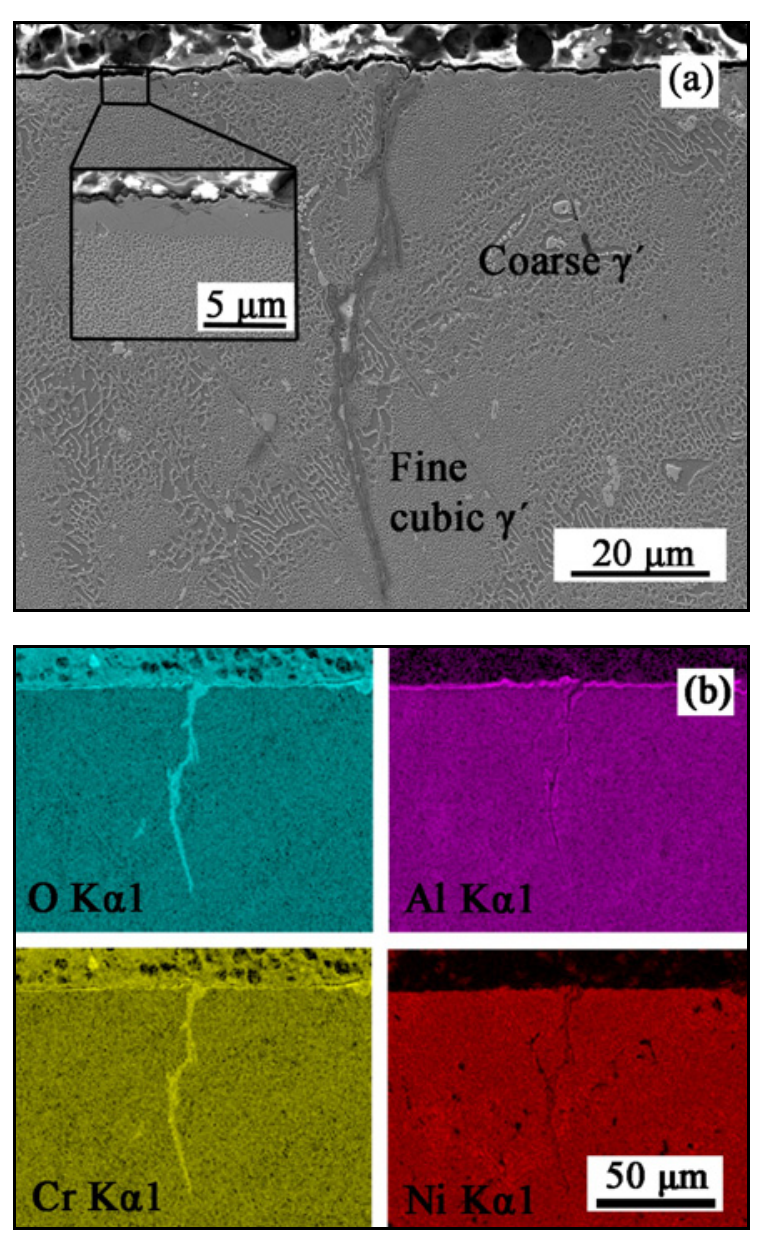

Fig. 3. (a) Fatigue crack in a section parallel to the loading axis of a specimen fatigue to fracture at $950^{\circ} \mathrm{C}$; (b) corresponding EDS analysis.

previously on different IN713 LC alloys [32, 33]. Casting defects (shrinkage pores) of the HIP treated and untreated material are shown in Fig. 4. Their maximum size reaches $0.62 \mathrm{~mm}$ for the untreated material, and $0.18 \mathrm{~mm}$ for the HIP treated material. The size, as well as distribution and number of defects, have a strong impact on mechanical properties. To assess an incidence of casting defects three cross sections of a total area of $11.7 \mathrm{~cm}^{2}$ were analysed. Defects were approximated by an ellipse, and the main ellipse axis was used to determine the maximal linear size of an individual defect [8].The dependence of the frequency of casting defects versus the linear size of defects is shown in Fig. 5. There is no doubt that HIP treatment not only reduces the size of these defects but also diminishes their amount.

\subsection{Dislocation structure}

Dislocation structure of both materials (HIP treated and untreated) was studied on selected speci-
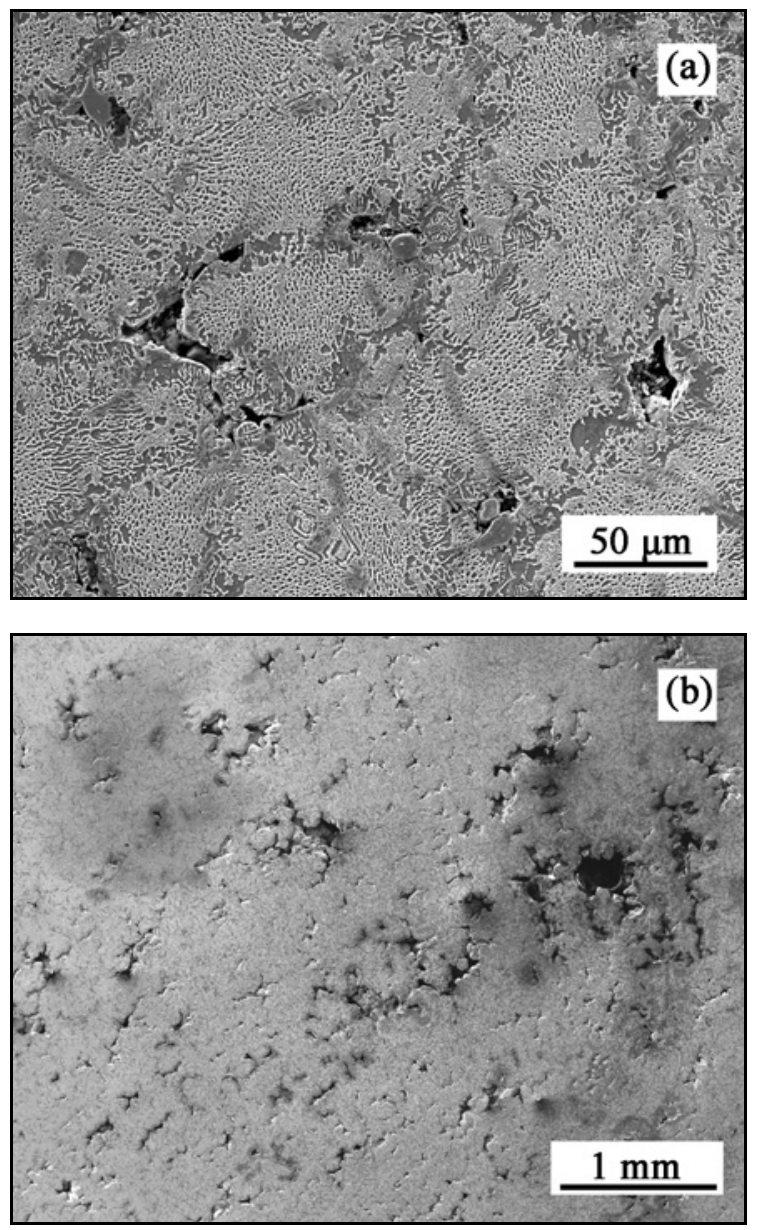

Fig. 4. Casting defects: (a) HIP treated and (b) untreated material.

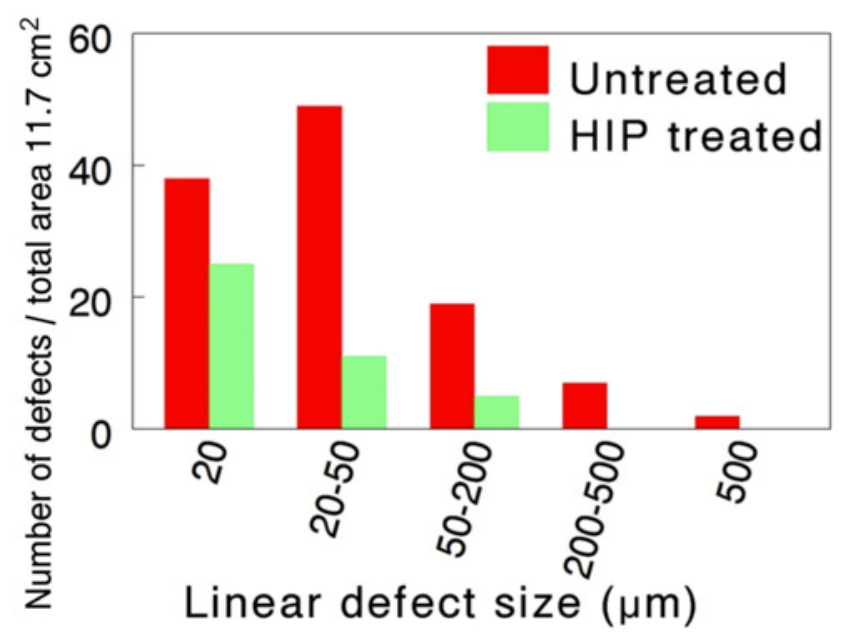

Fig. 5. Histogram of the frequency of defects depending on the maximal linear defect size measured on a total area of $11.7 \mathrm{~cm}^{2}$.

mens fatigued with different strain amplitudes to failure at 900 and $950^{\circ} \mathrm{C}$. TEM observations revealed pri- 

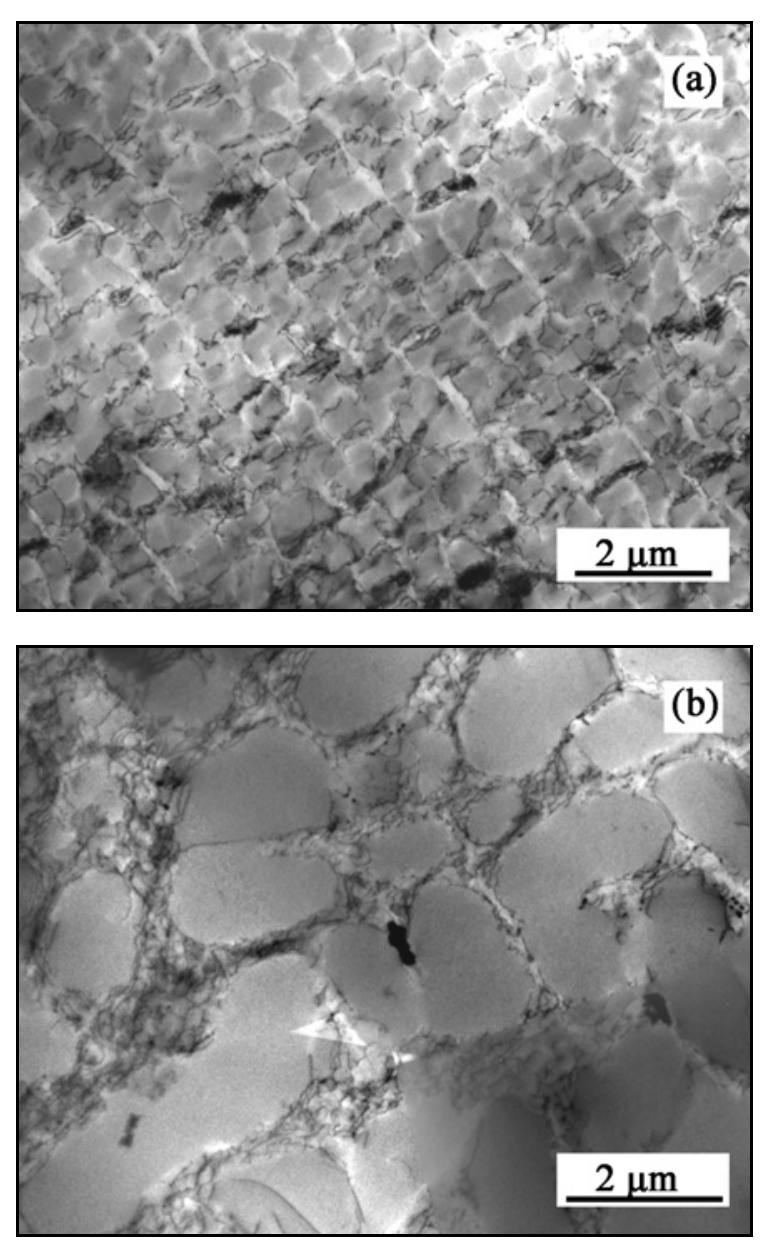

Fig. 6. TEM micrographs of dislocation structure in MAR-M247 after LCF: (a) area with cubic precipitates and (b) area with coarse precipitates $\left(\varepsilon_{\mathrm{a}}=0.5 \% ; N_{\mathrm{f}}=273 ; T=\right.$ $\left.900^{\circ} \mathrm{C}\right)$.

marily areas with regular distribution of cubic precipitates in the matrix - see Fig. 6a. In some places, coarse oval-shaped precipitates were also found in accord with SEM observations (Fig. 6b). Regardless treatment and test temperature both materials reveal similar dislocation behaviour. Figure 6 shows TEM micrograph taken from specimen cycled at high plastic strain amplitude. Figure 6a captures dislocation arrangement in an area with fine cubic precipitates. Dislocations are evenly spaced in the $\gamma$ channels and only rarely in the $\gamma^{\prime}$ precipitates. Figure $6 \mathrm{~b}$ shows a different location of the same grain with coarse precipitates. The situation is similar as in the area of fine precipitates. Dislocations are again homogeneously distributed in the $\gamma$ matrix channels and only rarely in the $\gamma^{\prime}$ precipitates. Specimen tested at low strain amplitude reveals some common features. Areas with coarse precipitates were similar with those observed in high amplitude domain. Only low dislocation density was observed in the gamma chan-
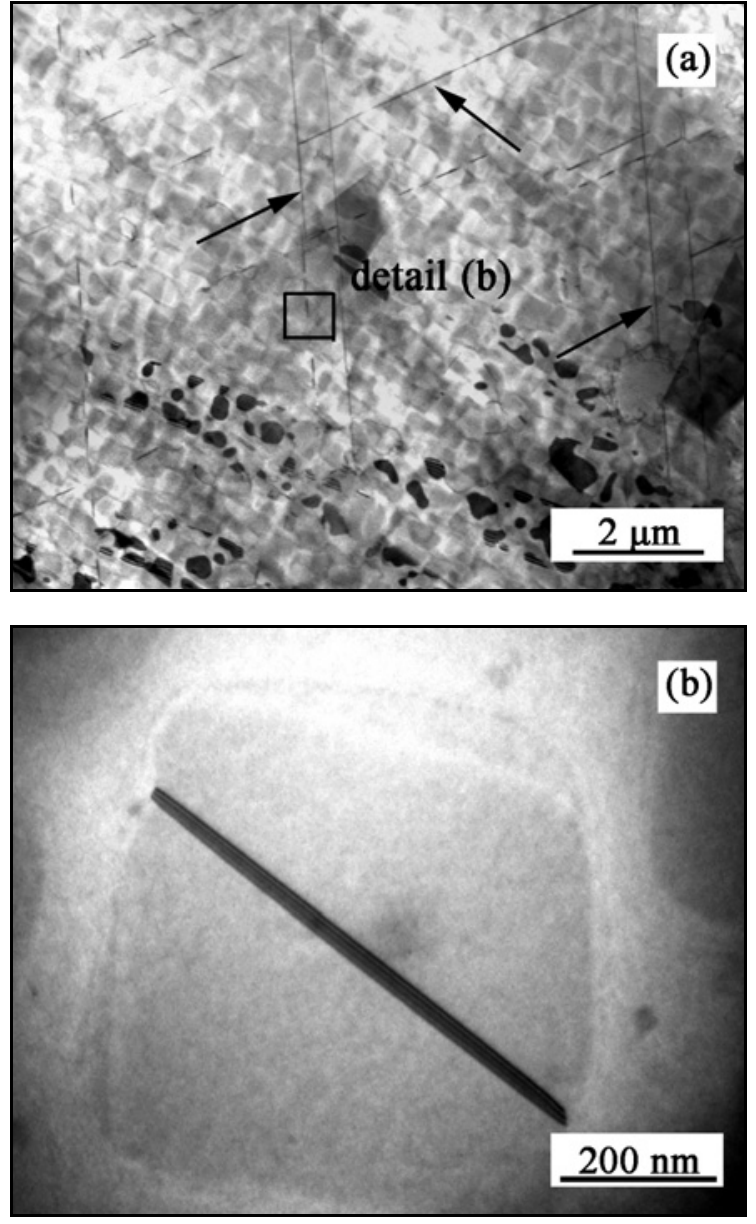

Fig. 7. TEM micrographs of dislocation structure in MARM247 of specimen cycled to fracture: (a) planar bands (indicated by arrows) going parallel to $\{111\}$ slip planes $\left(\varepsilon_{\mathrm{a}}=\right.$ $\left.0.19 \% ; N_{\mathrm{f}}=13784 ; T=900^{\circ} \mathrm{C}\right)$, (b) detail of planar band (area b).

Ta b le 1. Hardness and tensile properties of HIP treated and untreated MAR-M247

\begin{tabular}{cccc}
\hline & Untreated & \multicolumn{2}{c}{ HIP treated } \\
\hline HV 5 & $397 \pm 11$ & \multicolumn{2}{c}{$398 \pm 9$} \\
$T\left({ }^{\circ} \mathrm{C}\right)$ & 900 & 900 & 950 \\
$\sigma_{\text {UTS }}(\mathrm{MPa})$ & 719.1 & 733.7 & 648.3 \\
$\sigma_{\mathrm{y}}(\mathrm{MPa})$ & 641.1 & 647.5 & 574.6 \\
\hline
\end{tabular}

nels in areas with fine cubic precipitates as is apparent from Fig. 7. Figure 7 shows planar bands going through dendritic grains parallel to the primary slip planes $\{111\}$ (indicated by arrows) observed only at $900^{\circ} \mathrm{C}$. The bands contain fringes present only in the $\gamma^{\prime}$ precipitates and not in the $\gamma$ matrix. The fringes can be identified with antiphase boundaries formed by $a / 2<101>$ dislocations shearing the $\gamma^{\prime}$ precipitates. 

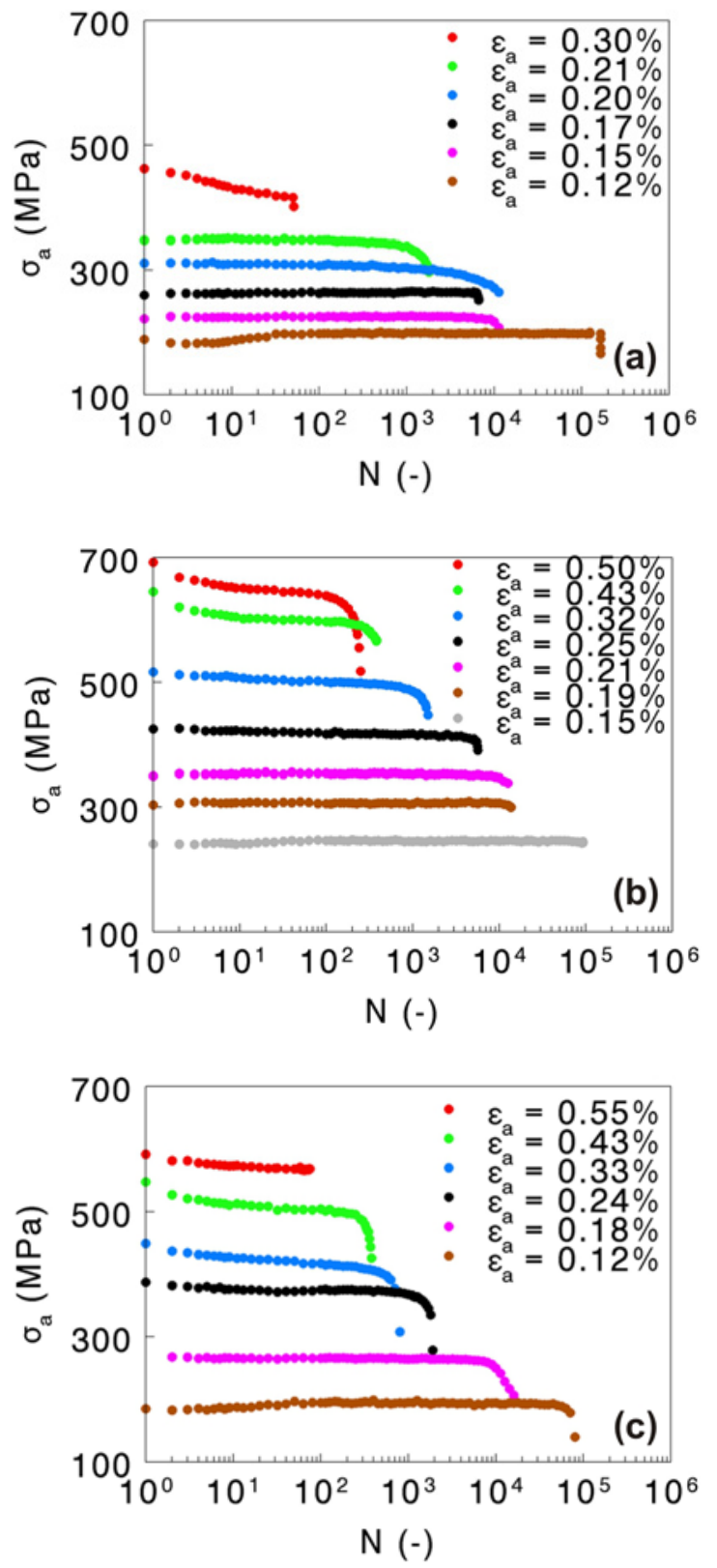

Fig. 8. Fatigue hardening/softening curves of MAR M247 for different total strain amplitudes $\varepsilon_{\mathrm{a}}$ : (a) untreated at $900{ }^{\circ} \mathrm{C}$; (b) HIP treated at $900^{\circ} \mathrm{C}$; (c) HIP treated at $950^{\circ} \mathrm{C}$.

\subsection{Mechanical properties}

\subsubsection{Tensile and hardness tests}

LCF test specimens were used to obtain experimental data from tensile tests performed on HIP treated and untreated material at $900^{\circ} \mathrm{C}$. Additional tensile test on HIP treated MAR-M247 was done at $950^{\circ} \mathrm{C}$. Strain rate was $\dot{\varepsilon}=2 \times 10^{-3} \mathrm{~s}^{-1}$. Tensile tests reveal slight differences in tensile properties of both materials (see Table 1). The Vickers test was

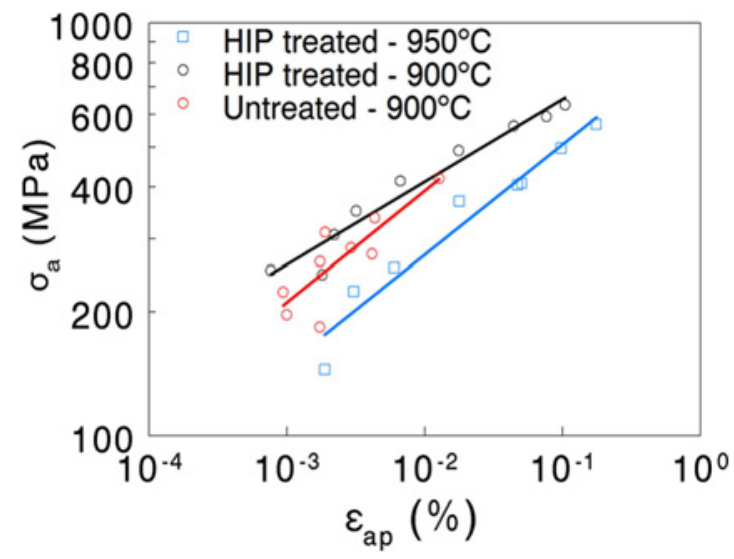

Fig. 9. CSSCs of HIP treated and untreated MAR-M247 at 900 and $950^{\circ} \mathrm{C}$.

used to determine the hardness of materials. Hardness tests were carried out on five randomly selected places at room temperature. The average hardness of both materials is shown together with standards errors in Table 1. No perceptible difference in Vickers hardness between both materials can be seen in Table 1 .

\subsubsection{Fatigue hardening/softening and cyclic stress-strain curves}

Fatigue hardening/softening curves in the representation of the stress amplitude $\sigma_{\mathrm{a}}$ versus the number of elapsed cycles $N$ are shown in Fig. 8 for both materials and temperatures. Figure $8 \mathrm{a}$ shows fatigue hardening/softening curves obtained at $900^{\circ} \mathrm{C}$ for untreated MAR-M247. It can be seen that the material has a stable stress response in the domain of low amplitudes and slight softening is observed for high amplitudes. Figures 8b,c show fatigue hardening/softening curves at 900 and $950^{\circ} \mathrm{C}$, respectively for material MAR-M247 treated by hot isostatic pressing technique. The character of the hardening/softening curves is similar at both temperatures. For low amplitude domain saturated stress response is apparent while softening can be seen at high amplitudes. The softening is accentuated with increasing strain amplitudes.

Cyclic stress-strain curves (CSSCs) of MAR-M247 were plotted in the form of the stress amplitude $\sigma_{\mathrm{a}}$ versus plastic strain amplitude $\varepsilon_{\text {ap }}$ at half-life. The cyclic stress-strain curves are shown in Fig. 9 in a bilogarithmic representation for both materials and both temperatures. The experimental data of $\sigma_{\mathrm{a}}$ vs. $\varepsilon_{\text {ap }}$ were approximated by the power law:

$$
\sigma_{\mathrm{a}}=K^{\prime} \varepsilon_{\mathrm{ap}}^{n^{\prime}},
$$

where $K^{\prime}$ is the cyclic hardening coefficient and $n^{\prime}$ is 
Table 2. LCF parameters of HIP treated and untreated MAR-M247 at 900 and $950{ }^{\circ} \mathrm{C}$

\begin{tabular}{lccccrc}
\hline Material $/ T_{\mathrm{t}}{ }^{*}\left({ }^{\circ} \mathrm{C}\right)$ & $K^{\prime}(\mathrm{MPa})$ & $n^{\prime}$ & $\varepsilon_{\mathrm{f}}^{\prime}$ & $c$ & $\sigma_{\mathrm{f}}^{\prime}(\mathrm{MPa})$ & $b$ \\
\hline Untreated $/ 900$ & $4600 \pm 2700$ & $0.267 \pm 0.056$ & $0.001+0.389 ;-0.001$ & $-0.408 \pm 0.065$ & $900 \pm 220$ & $-0.133 \pm 0.026$ \\
HIP treated $/ 900$ & $2600 \pm 410$ & $0.200 \pm 0.017$ & $0.22 \pm 0.16$ & $-0.860 \pm 0.078$ & $1950 \pm 180$ & $-0.173 \pm 0.010$ \\
HIP treated $/ 950$ & $3200 \pm 720$ & $0.267 \pm 0.026$ & $0.096 \pm 0.038$ & $-0.716 \pm 0.044$ & $1840 \pm 310$ & $-0.199 \pm 0.019$ \\
\hline
\end{tabular}

${ }^{*} T_{\mathrm{t}}$ is testing temperature

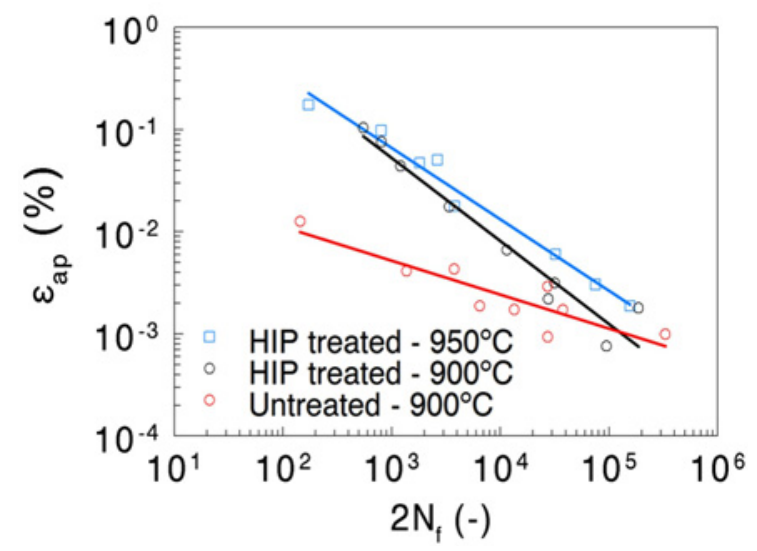

Fig. 10. Coffin-Manson fatigue life curves of HIP treated and untreated MAR-M247.

the cyclic hardening exponent. These parameters were determined by regression analysis for each material and temperature and are given in Table 2.

It can be seen that the CSSC of HIP treated material at $900{ }^{\circ} \mathrm{C}$ is slightly shifted to higher stress amplitudes in the low amplitude domain in comparison with the untreated material. Furthermore, an increase in temperature from $900^{\circ} \mathrm{C}$ to $950{ }^{\circ} \mathrm{C}$ results in a reduction of stress response for HIP treated material. The reduction is approximately $100 \mathrm{MPa}$ in the whole range of applied amplitudes.

\subsubsection{Fatigue life curves}

Fatigue life curves were determined as the total strain amplitude $\varepsilon_{\mathrm{a}}$, plastic strain amplitude $\varepsilon_{\text {ap }}$, and stress amplitude $\sigma_{\mathrm{a}}$ (both latter characteristics at half-life) versus the number of cycles to failure $N_{\mathrm{f}}$. The fatigue life curves in the representation of $\varepsilon_{\text {ap }}$ versus $N_{\mathrm{f}}$ are shown in a bilogarithmic plot in Fig. 10. Experimental data were approximated by the Coffin-Manson equation expressed in the form [34]:

$$
\log 2 N_{\mathrm{f}}=\left(\frac{1}{c}\right) \log \varepsilon_{\mathrm{ap}}-\left(\frac{1}{c}\right) \log \varepsilon_{\mathrm{f}}^{\prime},
$$

where $\varepsilon_{\mathrm{f}}^{\prime}$ is the fatigue ductility coefficient and $c$ is the fatigue ductility exponent. These parameters were determined by non-linear regression analysis and are listed in Table 2. Figure 10 compares Coffin-Manson

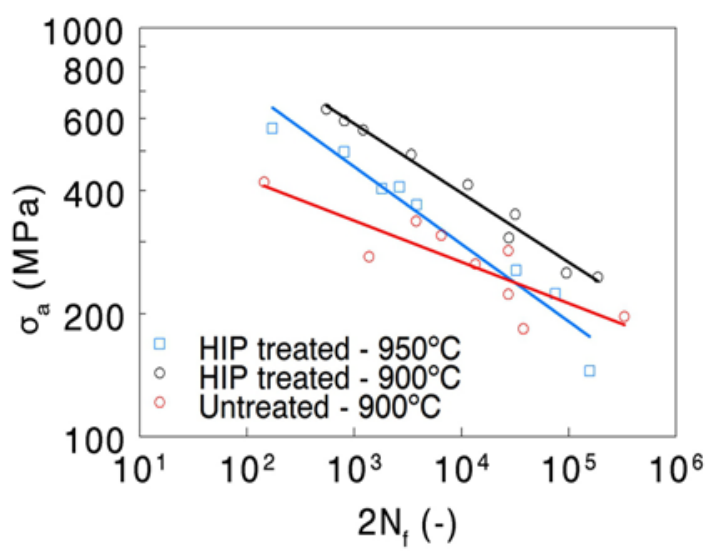

Fig. 11. Basquin fatigue life curves of HIP treated and untreated MAR-M247.

life curves of untreated material tested at $900^{\circ} \mathrm{C}$, and HIP treated material tested at temperatures of 900 and $950^{\circ} \mathrm{C}$. It is apparent that experimental points of the treated material strained at temperatures of 900 and $950^{\circ} \mathrm{C}$ lie close to each other. At a temperature of $900^{\circ} \mathrm{C}$, untreated MAR-M247 has a considerably lower fatigue ductility exponent in comparison with HIP treated superalloy. In the high amplitude domain, the fatigue life of the untreated material is sufficiently lower than that of the treated superalloy.

Fatigue life curves in the representation of stress amplitude $\sigma_{\mathrm{a}}$ versus the number of cycles to fracture $N_{\mathrm{f}}$ are plotted in Fig. 11. The Basquin law expressed in the form [34]:

$$
\log 2 N_{\mathrm{f}}=\left(\frac{1}{b}\right) \log \sigma_{\mathrm{a}}-\left(\frac{1}{b}\right) \log \sigma_{\mathrm{f}}^{\prime}
$$

was applied to fit experimental data. The fatigue strength coefficient $\sigma_{\mathrm{f}}^{\prime}$ and the fatigue strength exponent $b$ were evaluated using non-linear regression analysis, and their values are shown in Table 2 . It can be seen from Fig. 11 that the Basquin curve for HIP treated MAR-M247 at $900{ }^{\circ} \mathrm{C}$ is shifted to a higher lifetime in comparison with untreated material. The shift at $10^{2}$ and $10^{5}$ cycles is approximately 200 and $100 \mathrm{MPa}$, respectively. With the increase in temperature from 900 to $950{ }^{\circ} \mathrm{C}$, the fatigue life of HIP treated material is reduced by about 5 times while within experimental scatter the fatigue strength exponent is the same for both temperatures. 


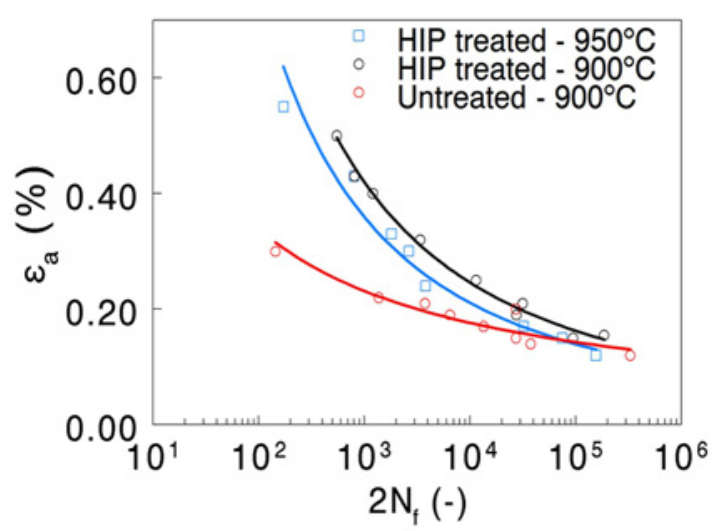

Fig. 12. Total strain amplitude $\varepsilon_{\mathrm{a}}$ versus a number of cycles to fracture $N_{\mathrm{f}}$ for untreated material at $900^{\circ} \mathrm{C}$ and HIP treated material at $900^{\circ} \mathrm{C}$ and $950{ }^{\circ} \mathrm{C}$.
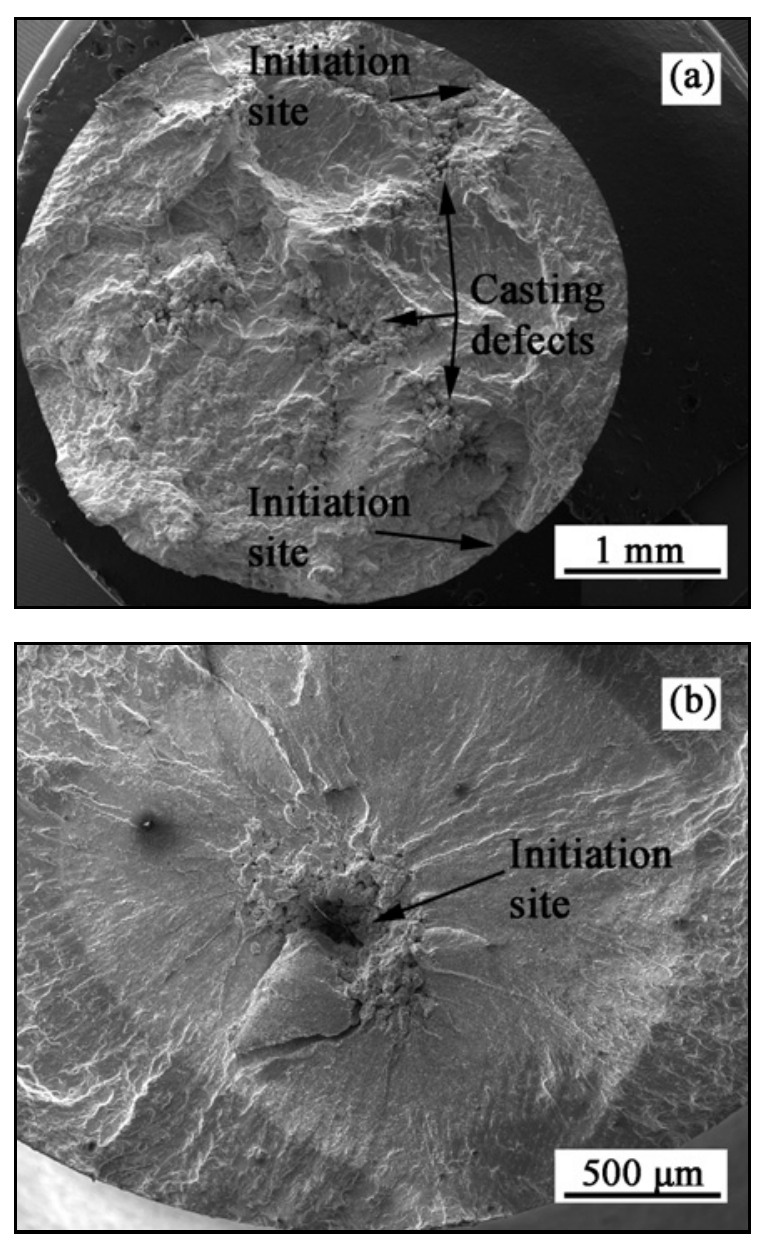

Fig. 13. Fracture surface of MAR-M247 after cyclic straining at $900{ }^{\circ} \mathrm{C}$ : (a) untreated $\left(\varepsilon_{\mathrm{a}}=0.19 \%, N_{\mathrm{f}}=3230 \mathrm{cy}-\right.$ cles); (b) HIP treated ( $\varepsilon_{\mathrm{a}}=0.19 \%, N_{\mathrm{f}}=13784$ cycles).

The total strain can be written as the sum of the elastic $\varepsilon_{\mathrm{ae}}$ and plastic deformation $\varepsilon_{\mathrm{ap}}$ [35]:

$$
\varepsilon_{\mathrm{a}}=\varepsilon_{\mathrm{ae}}+\varepsilon_{\mathrm{ap}}=\left(\frac{\sigma_{\mathrm{a}}}{E}\right)+\varepsilon_{\mathrm{ap}},
$$

where $E$ is Young's modulus. Substituting $\sigma_{\mathrm{a}}$ from Basquin law (Eq. 3) and $\varepsilon_{\text {ap }}$ from Coffin-Manson formula (Eq. (2)) we get the following equation:

$$
\varepsilon_{\mathrm{a}}=\left(\frac{\sigma_{\mathrm{f}}}{E}\right)\left(2 N_{\mathrm{f}}\right)^{b}+\varepsilon_{\mathrm{f}}^{\prime}\left(2 N_{\mathrm{f}}\right)^{c},
$$

which can be used to estimate the number of cycles to fracture under total strain control conditions. Figure 12 illustrates experimental data of the total strain amplitude versus a number of cycles to fracture for both materials tested at 900 and $950^{\circ} \mathrm{C}$. Fatigue life curves shown in Fig. 12 were acquired from Eq. (5) after substituting the parameters listed in Table 2. An average value of Young's modulus was used for the specific material at a particular temperature (161 and $169 \mathrm{GPa}$ for untreated and treated material at $900^{\circ} \mathrm{C}$, respectively, and $159 \mathrm{GPa}$ at $950^{\circ} \mathrm{C}$ for treated material).

\subsection{Fracture surface observation}

Figure 13 shows SEM micrographs of typical fracture surfaces of both materials after fatigue tests performed at $900^{\circ} \mathrm{C}$. Figure 13 a shows multiple initiations of fatigue cracks in the vicinity of casting defects near the surface and in bulk (see black arrows) of untreated MAR-M247 tested at $0.19 \%$ of total strain amplitude. Subsurface fatigue crack initiation from a casting defect inside the HIP treated specimen is depicted in Fig. 13b. The initial subsurface crack propagation without access of air resulted in the so-called fish eye. The specimen was strained at total strain amplitude of $0.19 \%$.

Fatigue crack initiation was observed in areas with coarse precipitates or at the interface of fine and coarse precipitates, where many $\mathrm{MC}, \mathrm{M}_{6} \mathrm{C}$ and $\mathrm{M}_{23} \mathrm{C}_{6}$ types of carbides are formed (see Fig. 2a). An example of this kind of fatigue crack initiation is apparent in Fig. $3 \mathrm{a}$ showing section parallel to the loading axis in a specimen fatigued to fracture at $950^{\circ} \mathrm{C}$. The crack nucleated at the surface grows initially across the coarse precipitates and then propagates at the interface of fine and coarse precipitates. Later the crack propagates even through the structure of fine precipitates.

Figure 14a shows a fatigue crack initiated at the grain boundary. At first, the crack grows along the grain boundary and later it changes to transcrystalline propagation. Figure 14b shows cracks initiated at carbides present in the specimen surface layer. High-temperature exposition causes carbides oxidation which results in the formation of stress concentrators and, consequently, fatigue cracks can nucleate (see Fig. 14b). 

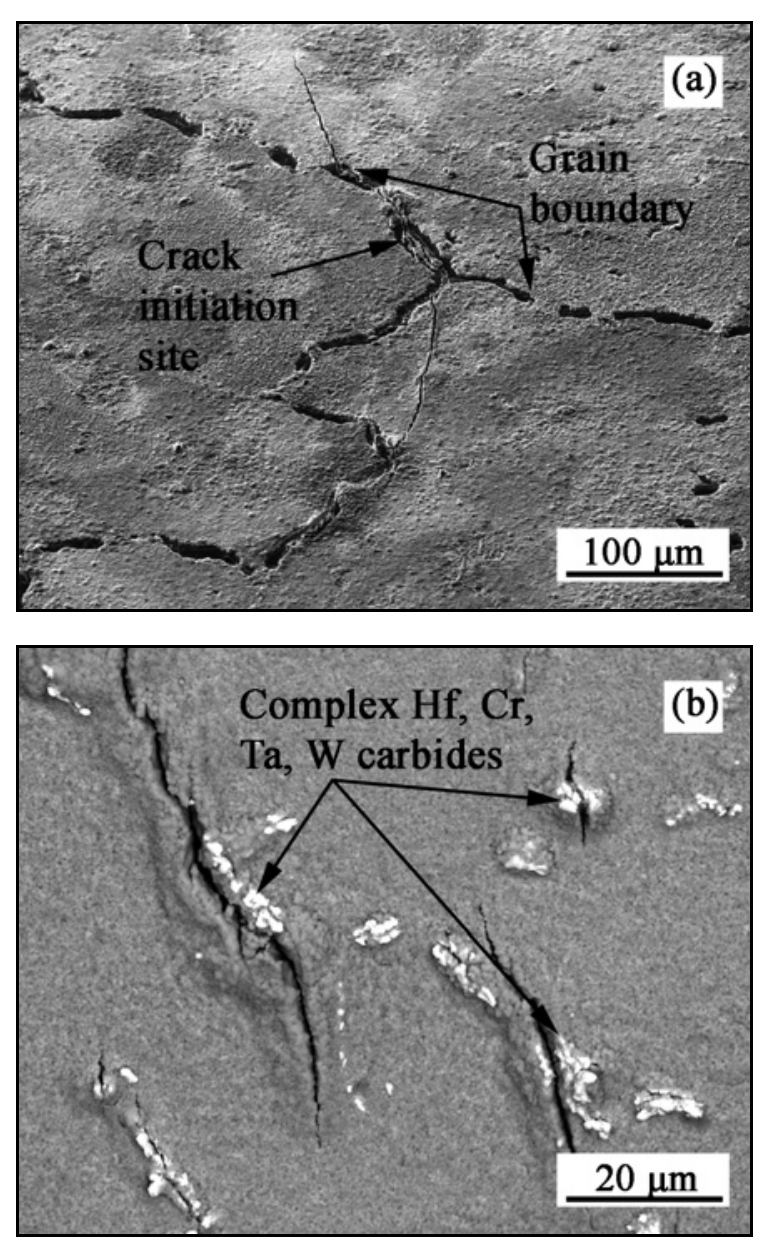

Fig. 14. A section parallel to the loading axis of a specimen cycled at $950^{\circ} \mathrm{C}-$ crack initiation at (a) grain boundary; (b) carbides (BSE image).

\section{Discussion}

\subsection{Microstructure}

In the present study, high-temperature low cycle fatigue of HIP treated and untreated MAR-M247 was studied. The microstructure of HIP treated and untreated MAR-M247 comprised strengthening phase heterogeneously distributed in $\gamma$ matrix (Fig. 2a). Areas with fine $\gamma^{\prime}$ precipitates with preponderantly cuboidal shape and areas of coarse $\gamma^{\prime}$ precipitates of more complex shape found in the present work are consistent with recent research [7, 8]. During LCF tests high-temperature exposure does not lead to directional coarsening of $\gamma^{\prime}$ precipitates indicating high stability of the alloy even at very high temperatures which is determined by a specific chemical composition stabilizing $\gamma$ matrix as well as $\gamma^{\prime}$ precipitates. Moreover, coarse and fine $\gamma^{\prime}$ precipitates impose a resistance to the movement of dislocations, which are at high temperature predominantly concentrated in the $\gamma$ matrix channels (Fig. 6). Carbide particles were observed mainly in the form of script and chains along grain boundaries and in interdendritic areas in accord with previous data [36, 37]. It was found that HIP treatment results in substantial reduction of casting defects both in size and the amount in comparison with the untreated material (see Figs. 4 and 5) in agreement with earlier works [8, 23-26]. Tensile tests at 900 and $950{ }^{\circ} \mathrm{C}$ and Vickers hardness test at room temperature of both material sets do not indicate a considerable change in tensile and hardness properties (as shown in Table 1) that can be addressed to casting defects. However, the detrimental effect of casting defects is more pronounced when alternate loading is involved - see section 4.3.

\subsection{Cyclic deformation behaviour of MAR-M247}

In the present work, it has been found that cyclic behaviour of MAR-M247 is closely related to the testing temperature, strain amplitude, and HIP treatment. Fatigue hardening/softening curves (Fig. 8) show that regardless temperature of cycling (900 or $950^{\circ} \mathrm{C}$ ) two areas can be distinguished. High and medium amplitudes result in cyclic softening whereas low amplitudes lead to stabilized stress response. Nature of cyclic deformation behaviour of nickel-based superalloys is particularly determined by the interaction between dislocations and $\gamma^{\prime}$ strengthening phase. Precipitates are an effective barrier to the movement of dislocations. However, cutting of precipitates by $a / 2$ $<110>$ dislocation pairs and slip bands formation is a well-known softening mechanism and was observed in a number of superalloys [5, 12, 34, 38-40].

Planar bands going through dendritic grains parallel to the primary slip planes $\{111\}$ were observed in the present work (see Fig. 7). Planar band characteristics indicate the presence of antiphase boundaries formed by shearing $\gamma^{\prime}$ precipitates with $a / 2$ $<110>$ dislocations. The motion of this dislocation leaves behind a crystal structure of the $\gamma$ matrix unchanged. The present results agree with the deformation mechanism reported previously on nickel-based superalloy polycrystals and single crystals [41, 42]. Further detailed study is needed to reveal the role of the planar bands in plastic strain localization and superalloy damage.

\subsection{Fatigue life}

Present results show that the fatigue life in the Coffin-Manson representation is almost temperature independent for the HIP treated material in the temperature interval of $900-950{ }^{\circ} \mathrm{C}$. The different slope in the Coffin-Manson curve of untreated and hipped superalloy at $900^{\circ} \mathrm{C}$ suggests different deformation 
mechanism. Crack initiation from large defects and subsequent growth accelerated by crack linking with defects is the dominant mechanism in untreated material. In HIP treated superalloy, it was shown that in addition to casting defects fatigue cracks also initiate in interdendritic areas and dendritic grain boundaries and at oxidized carbides - see Fig. 14. Early fatigue crack initiation at large defects in untreated material results in the shift of fatigue life curves to lower fatigue lives in comparison to HIP treated superalloy in the Coffin-Manson, Basquin, and total strain amplitude representation (see Figs. 10-12). Significant scatter in experimental data of untreated material could be attributed to random size and distribution of casting defects in agreement with previous results [21, 22]. The Basquin curve strongly depends on temperature - see Fig. 11. The increase in temperature from 900 to $950{ }^{\circ} \mathrm{C}$ results in a reduction of the fatigue life, e.g. for the stress amplitude of $300 \mathrm{MPa}$ the fatigue life reduces about 7 times.

\section{Summary and conclusions}

The second generation HIP treated and untreated nickel-based superalloy MAR-M247 was cyclically strained to failure at 900 and $950^{\circ} \mathrm{C}$. Based on the LCF tests, experimental data analysis and SEM and TEM observations, the following conclusions could be drawn:

1. Hot isostatic pressing treatment applied to material MAR-M247 resulted in a reduction of the average linear size of casting defects from 0.62 to 0.18 $\mathrm{mm}$.

2. MAR-M247 exhibits significant heterogeneity of gamma prime precipitates. Areas with the regularly arranged structure of cubic precipitates in the matrix and areas with roughened precipitates having oval-shaped morphology are observed in the both material conditions.

3. Dislocations are arranged primarily in the $\gamma$ matrix channels. Regardless the strain amplitude higher dislocation density is observed in areas with coarse precipitates in comparison with those of fine cubic precipitates. Planar slip bands containing antiphase boundaries are present in a specimens tested at $900^{\circ} \mathrm{C}$.

4. Fatigue life of HIP treated superalloy decreases with the temperature increase from 900 to $950{ }^{\circ} \mathrm{C}$ in Basquin representation while it is temperature independent in Coffin-Manson representation.

5. Fatigue cracks nucleate predominantly at the surface in the vicinity of casting defects. Some cracks were formed in areas with coarse precipitates or at the interface of coarse and fine precipitates and also at grain boundaries and carbide inclusions.

\section{Acknowledgements}

The present research was financially supported by the grant No. 15-20991S of the Czech Science Foundation (GACR) and by the grant No. TA04011525 of the Technology Agency of the Czech Republic (TACR).

\section{References}

[1] Benini, E.: Advances in Gas Turbine Technology. Rijeka, InTech 2011. doi:10.5772/664

[2] Whitesell, H. S., Overfelt, R. A.: Mater. Sci. Eng., 318, 2001, p. 264. doi:10.1016/S0921-5093(01)01264-3

[3] Nathal, M. V., Maier, R. D., Ebert, L. J.: Metal. Trans., 13, 1982, p. 1767. doi:10.1007/BF02647832

[4] Reed, R., Stoloff, T. N., Hagel, W. C.: The Superalloys: Fundamentals and Applications. Cambridge, Cambridge University Press 2008. doi:10.1017/CBO9780511541285

[5] Polák, J., Obrtlík, K., Petrenec, M., Man, J., Kruml, T.: Proc. Eng., 55, 2013, p. 114. doi:10.1016/j.proeng.2013.03.229

[6] Obrtlík, K., Pospíšilová, S., Juliš, M., Podrábský, T., Polák, J.: Inter. J. Fatigue, 41, 2012, p. 101. doi:10.1016/j.ijfatigue.2011.12.010

[7] Smíd, M., Kunz, L., Hutař, P., Hrbáček, K.: Proc. Eng., 74, 2014, p. 329. doi:10.1016/i.proeng.2014.06.273

[8] Sulák, I., Obrtlík, K., Skorík, V., Hrbáček, K.: In: Proceedings of $23^{\text {rd }}$ International Conference on Metallurgy and Materials "METAL 2014". Ostrava, Tanger Ltd. 2014, p. 1381.

[9] Šmíd, M., Horník, V., Hutař, P., Hrbáček, K., Kunz, L.: Transactions of the Indian Institute of Metals, 69, 2016, p. 393. doi:10.1007/s12666-015-0817-0

[10] Harris, K., Erickson, G. L., Schwer, R. E.: In: Proceedings of $5^{\text {th }}$ International Symposium "Superalloy". Warrendale, TMS 1984, p. 221.

[11] Kaufman, M.: In: Proceedings of $5^{\text {th }}$ International Symposium "Superalloy". Warrendale, TMS 1984, p. 43.

[12] Sims, CH. T., Stoloff, N. S., Hagel, W. C. (Eds.): Superalloys II. New York, John Wiley \& Sons 1987.

[13] Winstone, M. R.: Microstructural Stability of Creep Resistant Alloys for High Temperature Plant Applications. Cambridge, Cambridge University Press 1998.

[14] Milenkovic, S., Sabirov, I., Llorca, J.: Mater. Let., 73, 2012, p. 216. doi:10.1016/j.matlet.2012.01.028

[15] Bor, H. Y., Wei, C. N., Jeng, R. R., Ko, P. Y.: Mater. Chemistry and Physics, 109, 2008, p. 334. doi:10.1016/j.matchemphys.2007.11.041

[16] Rahimian, M., Milenkovic, S., Sabirov, I.: J. Alloys Comp., 550, 2013, p. 339. doi:10.1016/j.jallcom.2012.10.129

[17] Baldan, R., Rocha, R. L. P., Tomasiello, R. B., Nunes, C. A., Costa, A. M. S., Barboza, M. J. R., Coelho, G. C., Rosenthal, R.: J. Mater. Eng. Perform., 22, 2013, p. 2574. doi:10.1007/s11665-013-0565-4

[18] Zýka, J., Podhorská, B., Hrbáček, K.: In: Proceedings of $20^{\text {th }}$ Anniversary International Conference on Metallurgy and Materials "Metal 2011". Ostrava, Tanger Ltd. 2011, p. 1033. 
[19] Liao, J. H., Bor, H. Y., Wei, C. N., Chao, C. G., Liu, T. F.: Mater. Sci. Eng., 539, 2012, p. 93. doi:10.1016/j.msea.2012.01.059

[20] Baldan, R., Silva, P. R. S. A., Nunes, C. A., Coelho, G. C.: J. Mater. Eng. Perform., 22, 2013, p. 2337. doi:10.1007/s11665-013-0531-1

[21] Kunz, L., Lukáš, P., Konečná, R., Fintová, S.: Inter. J. Fatigue, 41, 2012, p. 47. doi:10.1016/i.ijfatigue.2011.12.002

[22] Smíd, M., Fintová, S., Kunz, L., Hutař, P.: MATEC Web of Conferences [online], 12, 2014. doi:10.1051/matecconf $/ 20141203005$

[23] Bor, H. Y., Hsu, C., Wei, C. N.: Mater. Chemistry and Physics, 84, 2004, p. 284. doi:10.1016/j.matchemphys.2003.08.014

[24] Chang, S. H.: Mater. Trans., 50, 2009, p. 909. doi: 10.2320/matertrans.MER2008435

[25] Chang, S. H., Lee, S. C., Tang, T. P., Ho, H. H.: Inter. J. Cast Metals Research, 19, 2006, p. 175. doi:10.1179/136404606225023399

[26] Li, J., Yuan, Ch., Guo, J., Hou, J., Zhou, L.: Progress in Natural Science: Materials International, 24, 2014, p. 631 doi:10.1016/i.pnsc. 2014.10 .008

[27] Polák, J.: Kovove Mater., 36, 1998, p. 171.

[28] Lukáš, P., Obrtlík, K., Kunz, L., Cadek, J.: Kovove Mater., 36, 1988, p. 205.

[29] Zrnik, J., Semenak, J., Hornak, P., Vrchovinsky, V.: Kovove Mater., 43, 2005, p. 93.

[30] Kunz, L., Lukáš, P., Mintach, R., Hrbáček, K.: Kovove Mater., 44, 2006, p. 275.

[31] Szczotok, A., Szala, J., Cwajna, J., Hetmańczyk, M.: Mater. Characterization, 56, 2006, p. 348. doi:10.1016/j.matchar.2005.10.011
[32] Sulák, I., Obrtlík, K., Celko, L., Gejdoš, P.: In: Proceedings of Multi Scale Design of Advanced Materials. Brno, Brno University of Technology 2015, p. 139. ISBN 978-80-214-5146-9

[33] Šulák, I., Obrtlík, K., Čelko, L.: Key Eng. Mater., 665, 2016, p. 73 doi:10.4028/www.scientific.net/KEM.713.86

[34] Obrtlík, K., Petrenec, M., Man, J., Polák, J., Hrbáček, K.: J. Mater. Sci., 44, 2009, p. 3305. doi:10.1007/s10853-009-3446-3

[35] Polák, J.: Cyclic Plasticity and Fatigue Life of Metals. Praha/Amsterdam, Academia/Elsevier 1991.

[36] Podrábský, T., Hrbáček, K., Obrtlík, K., Siegl, J.: In: Proceedings of $11^{\text {th }}$ International Metallurgical \& Material Conference "Metal 2002". Ostrava, Tanger Ltd. 2012, p. 75. ISBN 80-85988-73-9

[37] Podrábský, T., Juliš, M., Pospíšilová, S., Němec, K., Hrbáček, K.: Acta Metallurgica Slovaca, 1, 2005, p. 62.

[38] Prasad, K., Sarkar, R., Gopinath, K.: Mater. Sci. Eng., 654, 2016, p. 381. doi:10.1016/j.msea.2015.12.054

[39] Vorontsov, V. A., Shen, C., Wang, Y., Dye, D., Rae, C. M. F.: Acta Mater., 58, 2010, p. 4110. doi:10.1016/j.actamat.2010.03.041

[40] Sundararaman, M., Chen, W., Wahi, R. P.: Scripta Metall., 23, 1989, p. 1795. doi:10.1016/0036-9748(89)90363-3

[41] Jiao, F., Bettge, D., Osterle, W., Ziebs, J.: Acta Mater., 44, 1996, p. 3933. doi:10.1016/S1359-6454(96)00050-X

[42] Phillips, P. J., Unocic, R. R., Mills, M. J.: Int. J. Fatigue, 57, 2013, p. 50 doi:10.1016/j.ijfatigue.2012.11.008 